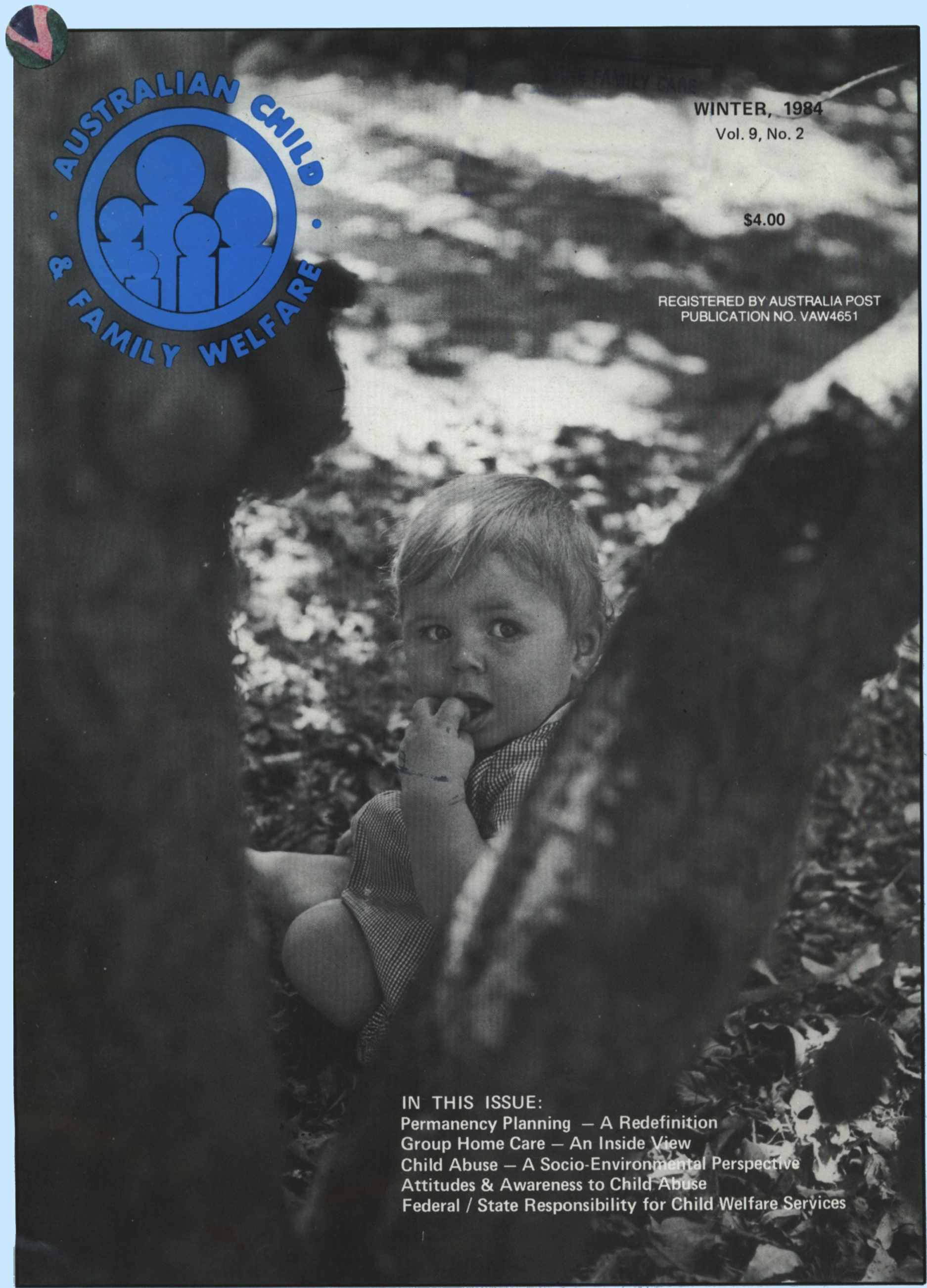




\section{IN THIS ISSUE EDITORIAL}

Margarita Frederico

\section{PERMANENCY PLANNING - a redefinition}

\section{A.N. Maluccio}

The author explores permanency planning and develops the concept in the light of practice and research findings.

\section{GROUP HOME CARE - an inside view}

Lesley Oakley

The author analyses the difficulties inherent in family group home programmes and suggests ways the limitations of such programmes can be minimized.

\section{CHILD ABUSE - a socio-environmental perspective}

Ro Roberts

In this, the first of two articles, the author describes a socio-environmental model of the family and argues strongly for its adoption in place of the family pathological model in work with families

\section{ATTITUDES \& AWARENESS TO CHILD ABUSE}

D. Shamley - S. Andrios - V. Athanasiou

In this article the authors report of research which sought to identify attitudes and awareness of a group of Greek families to child abuse.

\section{FEDERAL/STATE RESPONSIBILITY} FOR CHILD WELFARE SERVICES

\section{Susan Griffin}

The author reviews policies and priorities of Federal and State Governments in respect of child welfare and supports the creation of a Federal Ministry for Community Services. 